07;08

\title{
Синтез и свойства больших квантовых точек антимонида индия
}

\author{
(ㄱ Д.В. Крыльский ${ }^{1}$, Н.Д. Жуков ${ }^{2}$ \\ ${ }^{1}$ Научно-исследовательский институт прикладной акустики, Дубна, Московская обл., Россия \\ ${ }^{2} \mathrm{OOO} \mathrm{„НПП} \mathrm{Волга“,} \mathrm{Саратов,} \mathrm{Россия}$ \\ E-mail: krdvmail@mail.ru
}

Поступило в Редакцию 27 апреля 2020г.

В окончательной редакции 10 июня 2020г.

Принято к публикации 10 июня 2020 г.

Методами коллоидной химии при повышенных температурах $\left(250-300^{\circ} \mathrm{C}\right)$ синтезированы большие (до $20 \mathrm{~nm}$ ) квантовые точки (КТ) антимонида индия. По оптическим и электрофизическим характеристикам они проявляют свойства, подобные свойствам обычных КТ $(4-5 \mathrm{~nm})$, с тем отличием, что спектральный максимум люминесценции сдвинут неадекватно разнице в размерах. Это вместе с измерениями формы КТ методом просвечивающей электронной микроскопии может свидетельствовать об ухудшении совершенства кристаллической структуры больших КТ, возможно, по причине недостаточности температуры синтеза.

Ключевые слова: коллоидные квантовые точки, антимонид индия, синтез, люминесценция, вольт-амперные характеристики.

DOI: 10.21883/PJTF.2020.18.49995.18358

Синтез и свойства полупроводниковых коллоидных квантовых точек (КТ) изучаются почти 20 лет, при этом наибольшее число исследований посвящено широкозонным халькогенидам кадмия и среднещелевым халькогенидам свинца [1]. Перспективы расширения применения КТ в электронике связаны прежде всего с продвижением в инфракрасный и терагерцевый спектральные диапазоны, когда требуются узкозонные и бесщелевые полупроводники [2]. В связи с этим интересными являются полупроводники $\mathrm{A}_{3} \mathrm{~B}_{5}$, имеющие самый широкий диапазон свойств, наилучшие параметры размерного квантования и возможности большого выбора по разным требованиям. Одним из представителей группы полупроводников $\mathrm{A}_{3} \mathrm{~B}_{5}$ является антимонид индия $(\mathrm{InSb})$, для которого характерна экстремально малая величина эффективной массы электронов и дырок, что определяет относительно большой радиус экситона Бора (до $60 \mathrm{~nm}$ ) [3,4] и создает одно из преимуществ для практики - большой размер КТ, в которых может быть реализован режим сильного размерного квантования носителей, а не режим квантования экситона как целого. Однако увеличение размера КТ может привести к росту вероятности структурных искажений решетки при синтезе и ослаблению в ней квантово-размерных эффектов.

Научный и практический интерес к большим квантовым точкам обусловлен тем, что многие важные физические проявления определяются состояниями и поведением квазичастиц (экситоны, плазмоны и др.) и доменов, характеризующихся широким диапазоном микронной и субмикронной размерности [5]. Переход от микро- к наноразмерам обеспечит движение техники от СВЧ к терагерцевому диапазону.

Все эти обстоятельства делают важными и интересными синтез и исследования больших (до $20 \mathrm{~nm}$ ) квантовых точек антимонида индия (KT InSb-big). Информация об исследованиях, специально посвященных этому вопросу, в литературе крайне скудна $[3,4,6]$.

Цель настоящей работы - оптимизация метода синтеза коллоидных квантовых точек антимонида индия вплоть до размеров $20 \mathrm{~nm}$, а также анализ полученных результатов на основе исследования спектральных и вольт-амперных характеристик синтезированных КТ.

Коллоидный синтез КT InSb является проблемным из-за необходимости увеличения температуры (более $250^{\circ} \mathrm{C}$ ), длительности процесса и бедного выбора прекурсоров [7,8]. Нами выбран и опробован вариант коллоидного синтеза ядер KT InSb в среде безводного олеиламина с использованием в качестве прекурсоров смеси ацетата и коммерчески доступных трихлорида индия и триметилсилиламида сурьмы [9]. Добавка ацетата позволила свести к минимуму агрегационные процессы. Прекурсоры выдерживались в течение 20 min при перемешивании в среде аргона при $245^{\circ} \mathrm{C}$ для получения КТ со спектральным максимумом люминесценции $1050 \mathrm{~nm}$ (размер КТ 4-5 nm). Наращивание оболочки $\mathrm{CdS}$ проводилось с использованием в качестве прекурсоров растворов олеата кадмия $(0.2 \mathrm{M})$ и 1-октантиола $(0.24 \mathrm{M})$ в октадецене при температуре реакции $300-310^{\circ} \mathrm{C}$ в течение $60 \mathrm{~min}$. Наращивание оболочки InP осуществлялось с использованием трис-(диэтиламин) фосфина по методике [10].

В качестве растворителя применялся $0.05 \mathrm{M}$ Tris или фосфатный буфер (PBS). Дзета-потенциал определялся с помощью Malvern Zetasizer Z. Величины $\mathrm{pH}$ измерялись с использованием НI 211 pH-метра (Hanna Instruments). Электрофорез в агарозном геле осуществлялся в миниаппарате от Biorad (Richmond, CA). Центрифугирование проводилось с использованием микроцентрифуги Eppendorf 5417R (Brinkmann Instruments, Westburry, N.Y.). 
$a$
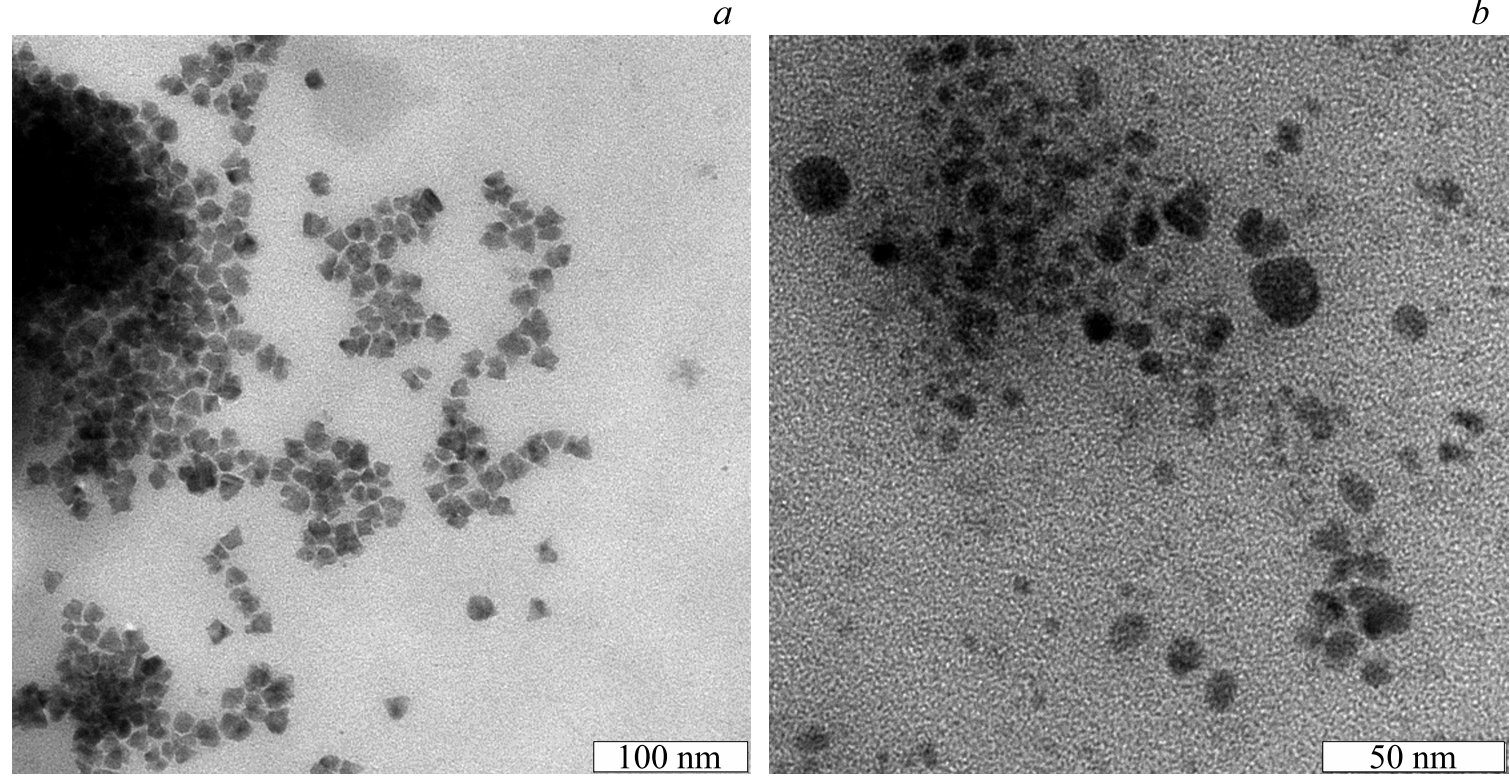

Рис. 1. ПЭМ-снимки островковых фрагментов квантовых точек. $a-\mathrm{KT} \operatorname{InSb}(\mathrm{InP} / \mathrm{CdS})$-smal, $b-\mathrm{KT} \operatorname{InSb}(\mathrm{InP} / \mathrm{CdS})-\mathrm{big}$.

Изготовленные по этой технологии квантовые точки с размерами $d \sim 4-5 \mathrm{~nm}$, как показали исследования [9], имели воспроизводимые размеры и относительно высокий уровень люминесценции в адекватно определяемом спектральном диапазоне с максимумом $1050 \mathrm{~nm}$. Для получения КТ с бо́льшими размерами $(d>5 \mathrm{~nm})$ увеличивались температура и время процесса синтеза. Были изготовлены КТ $\mathrm{InSb}(\mathrm{InP} / \mathrm{CdS})$-big и в качестве контрольных KT InSb(InP/CdS)-smal ( $d \sim 4-5 \mathrm{~nm})$.

Форма и размеры наночастиц контролировались методами сканирующей электронной микроскопии (СЭМ) на приборе Tescan Mira II LMU и просвечивающей электронной микроскопии (ПЭМ) на микроскопе Libra-120. Кривые распределения КТ по размерам, в том числе и в процессе длительного хранения в коллоидном растворе, измерялись методом динамического светорассеяния с помощью Malvern Zetasizer. Элементный состав слоя наночастиц на подложке контролировался методом СЭМ. Топология, параметры нанорельефа поверхности, вольт-амперные характеристики (ВАХ) контролировались прибором сканирующей атомно-силовой (ACM) и туннельно-токовой (СТM) микроскопии Nanoeducator-2 NT-MDT, предназначенным для измерений трехмерной картины и имеющим субнанометровое пространственное разрешение.

На рис. 1 приведены фрагментарные снимки ПЭМ-исследования на просвечивающем микроскопе Libra-120. На них при большом экранном увеличении установлены размеры КТ: $d \sim 4-5$ и $\sim 5-15 \mathrm{~nm}$. Необходимо отметить, что обе группы размеров наблюдались в обоих типах квантовых точек, причем для KT $\mathrm{InSb}(\mathrm{InP} / \mathrm{CdS})$-smal преимущественно наблюдалась группа с $d \sim 4-5 \mathrm{~nm}$. Кроме того, было установлено,

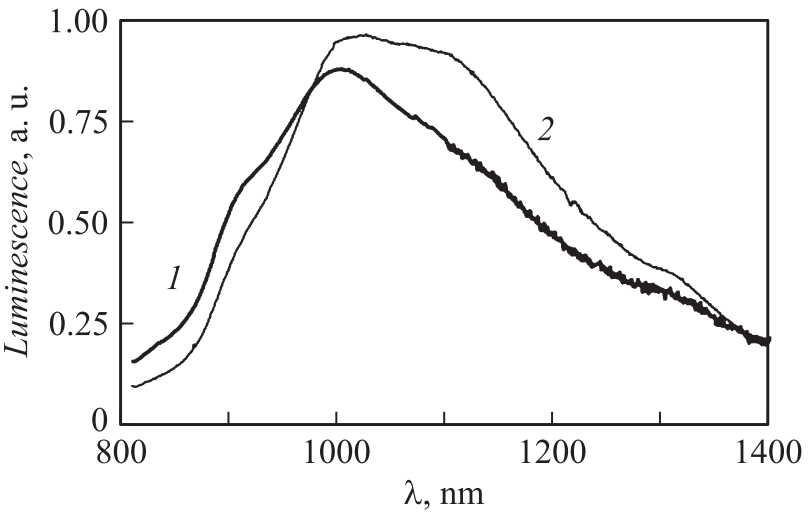

Рис. 2. Спектры фотолюминесценции. 1 - KT $\mathrm{InSb}(\mathrm{InP} / \mathrm{CdS})-$ smal, 2 - KT-InSb(InP/CdS)-big.

что в случае технологии синтеза КT $\mathrm{InSb}(\mathrm{InP} / \mathrm{CdS})$-smal форма КТ преимущественно квадратная и треугольная (рис. $1, a)$. Это может означать, что рост кристаллитов при синтезе происходит в направлениях, перпендикулярных плоскостям [100] и [111]; таким образом, в данном случае удается синтезировать КТ совершенной кристаллической структуры. Для случая КT InSb(InP/CdS)-big, наоборот, форма заметного числа частиц почти круглая (рис. $1, b)$, что может свидетельствовать о некоем несовершенстве структуры кристаллита.

Как хорошо известно, твердофазная структура кристаллизуется в неравновесных термодинамических условиях, обеспечиваемых уменьшением температуры, увеличением количества реагентов, влиянием ростовой затравки [11]. Совершенство кристаллической структуры в этом случае определяется прежде всего затравкой 

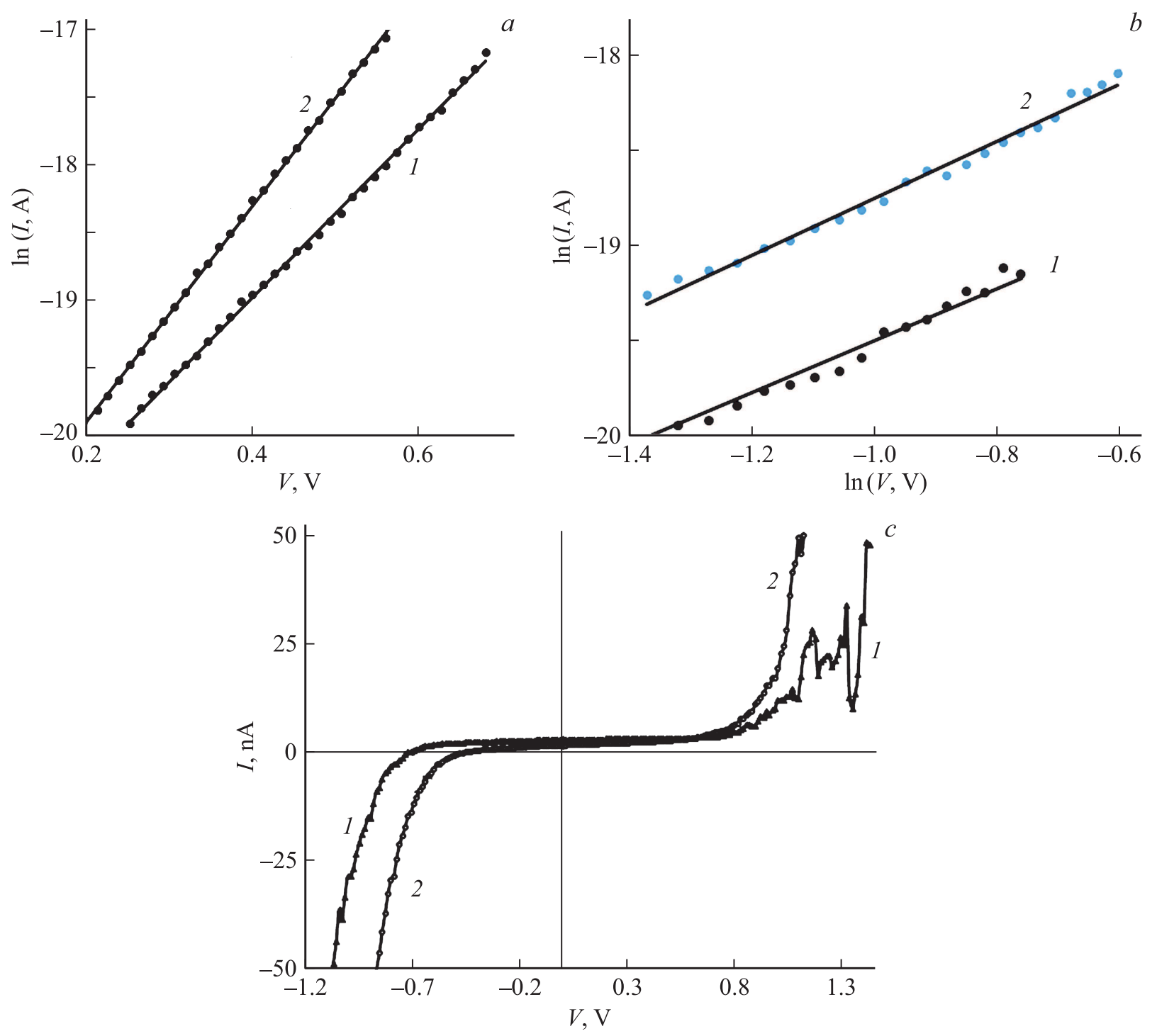

Рис. 3. Вольт-амперные характеристики в разных координатах: $a-$ полулогарифмических, „минус“ на образце; $b-$ логарифмических, „плюс“ на образце; $c$ - линейных. 1 - KT InSb(InP/CdS)-big, $2-\mathrm{KT} \operatorname{InSb}(\mathrm{InP} / \mathrm{CdS})$-smal.

(подложкой). Рассматриваемые же процессы коллоидного синтеза происходят при сугубо равновесных условиях (постоянстве температуры и концентрации реагентов), что на самом деле и способствует образованию совершенного кристаллита-зародыша в условиях самопроизвольного синтеза. Система кристаллита при этом образуется с термодинамической точки зрения за счет локальных флуктуаций температуры и концентрации, а скорость роста и кристаллическая структура определяются изменениями энергии и энтропии системы. При этом с разрастанием зародыша энергия кристаллита увеличивается, а энтропия уменьшается. Это ведет к тому, что для размера квантовой точки существует некий предел, при превышении которого кристаллическое совершенство становится плохо управляемым. Этот предел в нашем эксперименте наблюдается на уровне размера $d \sim 5 \mathrm{~nm}$ или, может быть, чуть более того.
Для увеличения этого значения необходимо увеличивать температуру реакционной среды заметно более $250^{\circ} \mathrm{C}$, что на самом деле проблематично. Размер и совершенство структуры КТ, очевидно, отразятся на их свойствах.

Спектры поглощения КТ, измеренные на спектрофотометре Varian Cary 100 Вio с шагом $\sim 1 \mathrm{~nm}$ в кювете размером $\sim 1 \times 1 \mathrm{~cm}$, и спектры фотолюминесценции, измеренные на спектрофлуориметре HORIBA Fluorolog-3, для КТ $\mathrm{InSb}(\mathrm{InP} / \mathrm{CdS})$-big были несколько сдвинуты в длинноволновую сторону (на $\sim 10 \%$ вместо ожидаемых 2-3 раз) относительно аналогичных спектров для KT $\mathrm{InSb}(\mathrm{InP} / \mathrm{CdS})$-smal и имели несколько бо́льшую ширину (рис. 2). Это может свидетельствовать о том, что основной вклад в люминесценцию в больших КТ вносит часть ядра примерно того же размера, что и ядро малых КТ. Периферийная же часть ядра вклада в 
люминесценцию не вносит, что может указывать на ее менее совершенную структуру.

BAX отдельных КТ обоих типов, многократно измеренные и усредненные, функционально не различались (рис. 3). Их различие определялось разницей в параметpax аппроксимации, которые связаны с долей падения напряжения на КТ, определяемой сопротивлением КТ, зависящим от ее размера. Линейный характер ВАХ в координатах $\ln I-V$ может свидетельствовать об эмиссионном характере тока [12], в координатах $\ln I-\ln V-$ об инжекции электронов в КТ и токе, ограниченном пространственным зарядом [13].

Исходя из характера BAX (рис. 3,c) - уменьшение и нестабильность тока - можно считать, что в интервале напряжений более $1 \mathrm{~V}$ имеет место кулоновская блокада подобно тому, как это обычно происходит в квантовых точках [14]. При этом на KT $\mathrm{InSb}(\mathrm{InP} / \mathrm{CdS})$-smal эффект не наблюдается за счет недостаточного падения напряжения и в связи с этим невыполнения энергетического условия проявления кулоновской блокады.

Таким образом, методами коллоидной химии при повышенных температурах синтезированы большие (до $20 \mathrm{~nm}$ ) квантовые точки антимонида индия. По оптическим и электрофизическим характеристикам они проявляют свойства, подобные свойствам обычных КТ (4-5 nm), с тем отличием, что спектральный максимум люминесценции сдвинут неадекватно разнице в размеpax. Этот факт и ПЭМ-наблюдение формы КТ могут свидетельствовать об ухудшении совершенства кристаллической структуры больших КТ, возможно, по причине недостаточности температуры раствора реагентов при синтезе.

\section{Благодарности}

Авторы благодарны С.В. Дежурову за изготовление наночастиц, М.В. Гаврикову за СТМ-измерения, И.Т. Ягудину за СЭМ- и ПЭМ-измерения.

\section{Финансирование работы}

Исследование выполнено при финансовой поддержке Российского фонда фундаментальных исследований в рамках научного проекта № 18-07-00586-а.

\section{Конфликт интересов}

Авторы заявляют, что у них нет конфликта интересов.

\section{Список литературы}

[1] Бричкин С.Б., Разумов В.Ф. // Успехи химии. 2016. Т. 85. № 12. C. 1297-1312.

[2] Reiss P., Carriere M., Lincheneau C., Vaure L., Tamang S. // Chem. Rev. 2016. V. 116. N 18. P. 10731-10819.

[3] Tamang S., Kim K., Choi H., Kim Y., Jeong S. // Dalton Trans. 2015. V. 44. P. 16923-16928.
[4] Liu W., Chang A.Y., Schaller R.D., Talapin D.V. // J. Am. Chem. Soc. 2012. V. 134. N 50. P. 20258-20261.

[5] Алёшкин В.Я. Современная физика полупроводников [Интернет-ресурс]. Режим доступа: http://www.pnn.unn.ru/ UserFiles/lectures/Aleshkin_lectures.pdf

[6] Mikhailov A.I., Kabanov V.F., Zhukov N.D., Glukhovskoy E.G. // Nanosystems: physics, chemistry, mathematics. 2017. V. 8. N 5. P. 596-599.

[7] Yaemsunthorn K., Thongtem T., Thongtem S., Randorn C. // Mater. Sci. Semicond. Process. 2017. V. 68. P. 53-57.

[8] Yarema M., Kovalenko M.V. // Chem. Mater. 2013. V. 25. N 9. P. 1788-1792.

[9] Крыльский Д.В., Жуков Н.Д. // Письма в ЖТФ. 2019. Т. 45. B. 16. C. $10-13$

[10] Shen W., Tang H., Yang X., Cao Z., Cheng T., Wang X., Tand Z., You J., Deng Z. // J. Mater. Chem. C. 2017. V. 5. P. 8243-8249.

[11] Лукашин А.В., Елисеев А.А. Химические методы синтеза наночастиц. Методические материалы. М.: МГУ, 2007 [Интернет-ресурс]. Режим доступа: http://www.ignorik.ru/ign/660/d-659553/7z-docs/3.pdf

[12] Жуков Н.Д., Мосиям Д.С., Синёв И.В., Хазанов А.А., Смирнов А.В., Лапшин И.В. // Письма в ЖТФ. 2017. Т. 43. B. 24. C. $72-79$.

[13] Жуков Н.Д., Хазанов А.А., Переверзев Я.Е. // Письма в ЖТФ. 2017. Т. 43. В. 12. C. 9-17.

[14] Kurzmann A., Stegmann P., Kerski J., Schott R., Ludwig A., Wieck A.D., König J., Lorke A., Geller M. // Phys. Rev. Lett. 2019. V. 122. N 24. P. 247403. 